\title{
Quantitative Literacy Interventions at University of Cape Town: Effects of Separation from Academic Disciplines
}

Vera Frith

University of Cape Town, vera.frith@uct.ac.za

Follow this and additional works at: https://digitalcommons.usf.edu/numeracy

Part of the Mathematics Commons, and the Science and Mathematics Education Commons

\section{Recommended Citation}

Frith, Vera. "Quantitative Literacy Interventions at University of Cape Town: Effects of Separation from Academic Disciplines." Numeracy 5, Iss. 1 (2012): Article 3. DOI: http://dx.doi.org/10.5038/ 1936-4660.5.1.3 


\title{
Quantitative Literacy Interventions at University of Cape Town: Effects of Separation from Academic Disciplines
}

\begin{abstract}
The aim of the Numeracy Centre at the University of Cape Town is to develop students' quantitative literacy (QL) in a manner consistent with their programmes of study and intended roles in the community. Our theoretical perspective on the nature of QL is in line with that of the New Literacies Studies and sees academic QL as practices in different academic disciplinary contexts. This means that for us the ideal curriculum structure for developing QL would fully integrate it into the teaching of the disciplines. This is in practice not achievable in most cases, especially since many students do not have the necessary foundations of mathematical and statistical knowledge and skills. The unavoidable deviation from the ideal curriculum structure presents challenges to the design of QL interventions. Two illustrative examples which display different degrees of separation from the disciplinary teaching are described and discussed. This discussion is based on lecturers' reflections on the teaching experience and on student evaluations. The 'stand-alone' QL course for Humanities and Law students, which uses a context-based approach, is the least integrated with the disciplinary curriculum, and presents challenges in terms of tensions in the classroom between the contexts and the mathematical and statistical content, as well as challenges in terms of student motivation. The QL intervention for medical students is more closely integrated into the medical curriculum and presents fewer challenges. Both interventions are intended to provide 'foundations' in terms of QL and suffer from difficulties in providing students with authentic motivation.
\end{abstract}

\section{Keywords}

quantitative literacy, numeracy, curriculum, higher education

\section{Creative Commons License}

\section{c) (i) (8)}

This work is licensed under a Creative Commons Attribution-Noncommercial 4.0 License

\section{Cover Page Footnote}

Vera Frith is the Co-ordinator of the Numeracy Centre, a unit within the Centre for Higher Education Development at the University of Cape Town. Her primary interest is the quantitative literacy development of university students and the development of appropriate curriculum for this purpose. 


\section{Introduction}

Many students in higher education in South Africa are poorly prepared to meet the QL demands of university curricula (Frith and Prince 2009, p. 83). For example, in the pilot tests of the National Benchmark Test Project in 2009 only one quarter of all students tested were classified as "proficient" in QL (Yeld 2009, p. 79). ${ }^{1}$ This level of unpreparedness in many cases is due to educational disadvantage, particularly of black students, resulting from the history of the education system in our country and from socioeconomic factors. The consequences of a disadvantaged education are often particularly severe in the area of quantitative competencies. Inequities in the results of schooling lead to inequity of access to higher education, but also to inequities of outcomes if they are not addressed by the university curriculum. Scott et al. (2007, p. 16) report, for example, that the completion rates after five years in South African universities in a variety of disciplines for black students are approximately half those of white students. Bearing in mind that the vast majority of the population is black, clearly these racially based inequities in terms of university graduates are both socially and economically undesirable. This is the environment in which the Numeracy Centre at the University of Cape Town (UCT) attempts to make a contribution to addressing inequity and improving educational outcomes by striving to develop students' QL.

This article will outline the theoretical view of QL that informs our understanding of curriculum for QL development. Some of the work of the Numeracy Centre at UCT will briefly be described and some of the challenges presented by two different models for QL intervention will be discussed. Both of these curriculum models deviate to different degrees from what we regard as the ideal degree of integration with the disciplinary contexts. The article focuses on the curriculum challenges arising from this deviation from the 'ideal.' Other challenges in courses of this nature, such as all those outlined by Dingman and Madison (2010), are also experienced in this course, but are not the focus of this article.

\section{The Numeracy Centre at UCT}

In 1998, when the creation of the Numeracy Centre was proposed, the University recognized in its Strategic Planning Framework document that "...UCT should ensure that each and every one of its graduates is ...effectively numerate ... at the

\footnotetext{
${ }^{1}$ Any student not classified as "proficient" in a given domain is deemed by the higher education sector to be unlikely to succeed in higher education without additional support in this domain. The National Benchmark tests cover Academic Literacy (which includes QL) and Mathematics.
} 
appropriate graduate level." A similar goal is currently reflected in a university concept paper: "We will seek opportunities within existing curricula to strengthen the basic 'literacies' - academic, quantitative and information - both as a means of improving learning capacity and as a contribution to informed citizenship."

In the proposal for the creation of the Numeracy Centre, it was argued that to achieve this goal "... what is required at this stage is a structure that can effect the necessary coordination and give permanency to the endeavour." The argument was that such a Centre could encourage positive initiatives by ensuring the best use of available expertise and resources through coordination, research and evaluation. Thus the Numeracy Centre can be seen as 'cross-cutting unit' that is involved in educational development at the faculty level, the programme ${ }^{2}$ level, or the course level, depending on circumstances.

In its first year of existence in 1999 the Numeracy Centre staff was responsible for teaching one full-year course for extended programme ${ }^{3}$ students bound for studies in Commerce. Over the last ten years we have expanded our activities to the point where we now annually deliver five semester courses for Law and Humanities students, have five substantial interventions in the medical (MBChB) programme, and deliver extensive computer-based materials for second-year psychology and for third-year sociology students. In addition, we are involved in other smaller interventions and new work under development. All our major courses and interventions provide for 'mainstream' students as well as students on extended programmes.

\section{Defining Quantitative Literacy}

Our view of QL is consistent with Gee's (1990, p. 151) notion of secondary Discourse and the approach of the 'New Literacy Studies' (p. 49) which sees all literacies as social practice. Gee introduced the notion of "Discourses" which "demand certain ways of using language, certain ways of acting and interacting, and the display of certain values and attitudes" (p. xvii). He indicated that there are different Discourses associated with different academic disciplines ("subject matters") and saw these as examples of "secondary Discourses" (p. 151). He went on to define literacy as "mastery of, or fluent control over, a secondary Discourse" (p. 153) and pointed out that as there are many different Discourses there will be multiple literacies.

\footnotetext{
${ }^{2}$ We use the term 'programme' to describe the set of courses leading to a specific qualification, for example 'Social Work', or 'Philosophy, Politics and Economics.'

${ }^{3}$ Extended programmes in South Africa are four-year (as opposed to 'mainstream' three-year) degree programmes intended for students who demonstrate potential but who would not automatically be admitted on the basis of their school results. Students in these programmes are given extra support and take dedicated 'foundation' courses, particularly in their first year.
} 
This theory underlies the New Literacy Studies' approach, which conceptualises literacy and numeracy as social practice (Kelly et al. 2007; Street 2005; Street and Baker 2006). In talking about academic literacy, McKenna (2009, p. 21) expresses this by saying we need to understand the academic disciplines as "communities requiring certain literacy practices of their members." As there are different QL practices associated with different academic disciplines, it makes little sense to talk about being quantitatively literate, independently of the Discourse where this literacy is to be practised.

In the Numeracy Centre we adopt the following definition of QL:

Quantitative literacy is the ability to manage situations or solve problems in practice, and involves responding to quantitative (mathematical and statistical) information that may be presented verbally, graphically, in tabular or symbolic form; it requires the activation of a range of enabling knowledge, behaviours and processes and it can be observed when it is expressed in the form of a communication, in written, oral or visual mode (Frith and Prince 2006, p. 30).

The development of this definition was most strongly influenced by the definition of numerate behaviour underlying the assessment of numeracy in the Adult Literacy and Lifeskills (ALL) Survey (Gal et al. 2005, p. 153) and the view of literacy as social practice. It overlaps to a large extent with what some writers refer to as "document literacy" (Mosenthal 1996, p. 314) as well with "statistical literacy" (Gal 2005, p. 48) and "graphicacy" (Roth et al. 2005, p. xi). Quantitative literacy often also includes a degree of computer literacy, as quantitative information is frequently accessed electronically and in many situations computer use will be a component of the relevant "enabling knowledge, behaviours and processes".

Given that QL practice is embedded in an academic Discourse and language is integral to any Discourse, it is clear that the development of QL cannot be disentangled from language development. Quantitative information and concepts are conveyed through language, often using precise terminology and disciplinespecific forms of expression which are associated with specific quantitative ideas. A student will not encounter this kind of expression in isolation, but will have to interpret it and use it embedded in the language of the disciplinary Discourse.

\section{Views on Ideal Curriculum for Quantitative Literacy}

Quantitatively literate behaviour can be understood in terms of (a) the contexts that require the QL practice; (b) the mathematical and statistical concepts and techniques (content) that are required by the practice and (c) the underlying thinking and competencies that are called upon, for example, the ability to interpret data or quantitative text and to write statements about it or to ask critical questions about its validity. In this article the term 'disciplinary context' is used to 
refer to the context in which the student is expected to practise QL within an academic discipline. For example, for a Law student the 'disciplinary context' might be that of a case being studied in a Law course, while the 'content' will be the necessary mathematics or statistics required to understand the case.

The students will experience both the information about the 'disciplinary context' and the quantitative information as part of the disciplinary secondary Discourse. Thus we maintain that the development of students' QL (and other literacies) should be integrated into the disciplinary curriculum, and ideally not made the responsibility of a separate add-on course (or separate workshops provided by a QL 'expert'). Jacobs (2007, p. 872), in writing about academic literacy generally, says that students are inducted into Discourses by modelling themselves on 'insiders' and that therefore "discipline-specific academic literacies are best taught by 'insider' disciplinary lecturers who have mastered the Discourses of those particular academic communities." However, for university lecturers whose QL practices are fluent in their discipline, these practices become transparent and it is difficult to recognise explicitly the tacit quantitative demands placed on students (Jacobs 2007, p. 871). In addition they are not necessarily knowledgeable about teaching the required quantitative concepts and procedures. The ideal situation for us would be for the Numeracy Centre lecturers to work alongside the disciplinary lecturers to enable them to respond to the QL needs of the students within their teaching. However, for various reasons (historical, political, structural and practical) this kind of engagement is often not possible, which means that much of our work consists of providing 'stand-alone' courses or isolated workshops. These courses have a 'context-based' curriculum in that we select the 'contexts' in which the students must practice quantitative literacy within our courses. Thus we make a distinction between the 'contexts' in our courses and the 'disciplinary contexts' in which we are preparing our students to practice. The degree of match between the 'contexts' and the 'disciplinary contexts' varies for different QL interventions.

In spite of the arguments for embedding the development of QL within Discourses, there is one respect in which we need to be cautious. Quantitative literacy is different from other literacies in that there is mathematical and statistical content which must be part of the curriculum for QL interventions, however they are structured. In thinking about how to weave the teaching of this content into the curriculum, we must be mindful of the evidence (Lerman and Zevenbergen 2004, p. 40; Venkat et al. 2009, p. 85; Zevenbergen et al. 2002, p. 8) that teaching mathematical skills in a context can cause students who have less developed language or academic literacy to become confused about what learning is valued, making the learning less effective. This means that we need to take particular care when designing and delivering a context-based QL curriculum, especially if it caters for students who have been educationally disadvantaged. 


\section{Two Quantitative Literacy Interventions at UCT}

In this section two of the QL interventions at our institution will be described. Some of the challenges they present will be discussed in the light of the degree to which they deviate from what we regard as ideal. Firstly our first-semester 'standalone' course for Humanities and Law students will be outlined. This course is integrated with the disciplines only in so far as the contexts we choose for our materials are relevant to the study of these disciplines. Our intervention for the first-year medical (MBChB) students will then be described. This intervention has a fairly high degree of integration with the medical course's disciplinary contexts, but is still delivered in a spatially and temporally distinct manner.

\section{The QL Course for Humanities and Law Students}

Description of the Course. Law students and Humanities students intending to study psychology or economics complete essentially the same QL course provided by the Numeracy Centre in the first semester, although they are taught separately and register under different course codes. Law students complete only this single-semester course, while Humanities students follow it up with a secondsemester course, either focusing on research methods or on pre-calculus mathematics (for psychology and economics students respectively). In this article only the first-semester QL course will be discussed. The students who take this course are either registered on an extended degree programme, in which case it can be considered a 'foundation course,' or are required to complete the course as a result of their performance on the National Benchmark Test for QL.

The course has the general objectives that students should be able to: (a) read text, tables and graphs containing quantitative information critically and with understanding; (b) express quantitative information in clear English, using tables and graphical representations where appropriate and (c) use a spreadsheet application to analyse and represent data. A considerable focus of the teaching in the course is on laying down the necessary foundations in mathematical and statistical content knowledge and skills, but this is always done in context.

Since 2009, the first half of the curriculum of this course has been structured around three contexts: a module on children's rights, followed by one on xenophobia and then one on prison overcrowding. In the three context-based modules we present students with edited extracts from research reports of the kind which we believe they will encounter in their disciplinary studies and professions. The extracts are accompanied by comprehension-type questions which are used as a basis for workshops in which students are assisted in making sense of the quantitative information presented in the contextual material. An example extracted from the course materials is included in Appendix A. 
In these modules students engage with substantial real contexts, and the necessary mathematics and statistics that arises is developed as needed. Thus, the underlying organisational principle for the curriculum is the contexts, not the coherent development of mathematical and statistical content knowledge, although this content knowledge is very often the major focus of attention. The motivation for this curriculum structure is that it more closely mimics the reality of the QL practice in the disciplines and we assume this will facilitate transfer of the relevant quantitative competencies.

Table 1 presents a summary of the curriculum for the three context-based modules in the first half of the course (which are presented in the course in the order that they appear in the table). Unlike the intervention itself, this summary is structured around the main mathematical and statistical content so as to expose the topics that we believe are important.

Table 1

Summary of Mathematical and Statistical Content Covered by the Three Context-based Modules in the QL for Humanities and Law Course.

\begin{tabular}{|c|c|c|c|}
\hline \multirow[b]{2}{*}{ Content topic: } & \multicolumn{3}{|c|}{ Context module } \\
\hline & $\begin{array}{c}\text { Children's } \\
\text { rights }\end{array}$ & $\begin{array}{l}\text { Xeno- } \\
\text { phobia }\end{array}$ & $\begin{array}{c}\text { Prison over- } \\
\text { crowding }\end{array}$ \\
\hline Fractions & $\times$ & & $\times$ \\
\hline Negative numbers & & $\times$ & \\
\hline Ratios & $\times$ & $x$ & $\times$ \\
\hline Probability & $\times$ & & \\
\hline Percentages: absolute number vs. percentage & $\times$ & $x$ & $\times$ \\
\hline Calculating a percentage & $x$ & $x$ & $\times$ \\
\hline Calculating the whole given the percentage & $x$ & & \\
\hline Expressing the size of a change as a percentage & $x$ & $\times$ & $\times$ \\
\hline Increasing or decreasing by a given percentage & $\times$ & $x$ & \\
\hline Calculating the value before a percentage change & $\times$ & & \\
\hline Change in percentage points & $\times$ & $\times$ & $\times$ \\
\hline Compound change & $x$ & & \\
\hline Tables & $x$ & $x$ & $\times$ \\
\hline Bar charts & & $x$ & $\times$ \\
\hline Pie charts & $\times$ & $\times$ & $x$ \\
\hline Line charts & $x$ & $\times$ & $\times$ \\
\hline Scatter plots and line of best fit & & $\times$ & \\
\hline Frequency tables and charts & $\times$ & $\times$ & $x$ \\
\hline Sampling and bias & & $x$ & \\
\hline Sampling and confidence intervals & $\times$ & & \\
\hline Average & $x$ & & \\
\hline Rank, range, quartiles, quintiles, interquartile range & $x$ & & \\
\hline Scientific Notation & $x$ & & \\
\hline Significant figures & $\times$ & & \\
\hline Variables & & $\times$ & \\
\hline Area of a square and a rectangle & & & $\times$ \\
\hline
\end{tabular}

The second half of the course, which deals with financial mathematics and descriptive statistics, retains the structure which we used previously for the whole course, where the modules are built around the different categories of mathematical and statistical content, although the material is always presented in 
authentic or realistic contexts. The weekly computer-based learning tutorials are intended mainly to support the learning of data-analysis and representation as well as to teach students how to use a spreadsheet application for these purposes. The spreadsheet application used is Microsoft Excel, because Microsoft Office is available in our student computer laboratories and is widely used in South Africa.

Challenges in the QL for Humanities and Law Course. It has been argued that the ideal curriculum for QL development would completely integrate it into the disciplinary curriculum. However, for structural and historic reasons, the programme structure we are working within for the Humanities and Law students is in fact a separate QL course which they experience in their first semester of first year. As a result, the integrating of the QL competencies into suitable contexts must be done by designing learning materials that strive to present the necessary mathematical and statistical knowledge and procedures within contexts that we believe closely mimic those of the disciplines.

There is a fundamental contradiction underlying this course. The curriculum structure that dictates that the development of students' QL is addressed in a separate course early in their programme appears to assume that a literacy can be treated as a "generic mode" (Bernstein 2000, p. 53) in which the voice of the discipline is necessarily weak (Ashwin 2009, p. 94). However, the nature of QL itself (a practice embedded in a Discourse) dictates that strong integration with the disciplinary courses would be ideal for its development.

The "recontextualisation" (Bernstein 1990, p. 183) of the practices of, say, law or psychology into pedagogic Discourse ensures that the disciplinary curriculum is already at one remove from the authentic disciplinary practices. It is possible to view the process of curriculum design for our QL course as a further recontextualisation of the disciplinary curriculum. This double level of recontextualisation is a compromise necessitated by the deviation of the curriculum structure (at the programme level) from what we regard as the ideal on the basis of our understanding of the nature of QL.

The fact that our teaching of QL is at two removes from the practices for which students are being educated contributes to the tensions we experience between the content and the contexts in the implementation of this course (Frith et al. 2010). A major challenge is the selection of contexts that will exemplify the disciplinary Discourse that these students will encounter in other courses. Given our experience that many of our students have significant difficulties with the mathematical and statistical content, the contexts we choose must not demand a great deal of specialized knowledge, as we cannot afford the time to teach students about the features of specific contexts.

In this respect, there are two main challenges we face when teaching the course. Firstly, we have seen that we may have unrealistic expectations for 
students' familiarity with the contexts we have chosen and with the meanings of ordinary English words associated with them. For example in one workshop some students defined the word 'nation-wide' used in the text as meaning 'all over the world' and many made no distinction in meaning between the words 'migration' and 'immigration.' We expect students to have difficulties with the language used to express quantitative concepts, but we do not always judge correctly their level of familiarity with the language used in the disciplinary discourse. Secondly, many students do not appear to be interested by the contexts and engage superficially with them. Insight and understanding of the contexts is not the main focus of our course or its assessment, and the consequent lack of authentic motivation to engage with the contexts is understandable within the framework of the double level of recontextualisation discussed above.

The result of these difficulties is that we have had to spend more time than we anticipated on helping students to understand the contexts and their associated language, which reduces the time available for teaching the mathematics and statistics concepts. In addition the fact that different mathematical and statistical concepts arise in the course as required by the contexts, and not by a coherent exposition of the mathematical structure, means that some of the students do not build up a coherent understanding of the underlying structures of the mathematics content.

Although we believe the contexts used in the course are authentic to the disciplines, the students have a naive view of what the disciplines entail and insufficient experience to appreciate the relevance of the contexts we have chosen for our course. This is a difficulty inherent in delivering a foundational QL course, (and often also applies to the students' perception of the relevance of the course as a whole, including its mathematical and statistical content). This is supported by the results of a relatively informal survey carried out amongst our past students, which fortunately revealed that some of them do come to appreciate the course and see it in a positive light as they progress through their programmes. E-mail questionnaires were sent to 350 Humanities students who had passed our firstyear QL courses in previous years (of which the course described in this article is the first). Since only 45 voluntary replies were obtained, these are obviously not representative, but they do provide some reassurance that the courses are achieving at least some of their goals. The results for two of the questions relating to student perceptions are summarised in Figure 1 and show how some students' attitude towards the courses and their relevance and usefulness becomes more positive as they progress through their programme of study. 

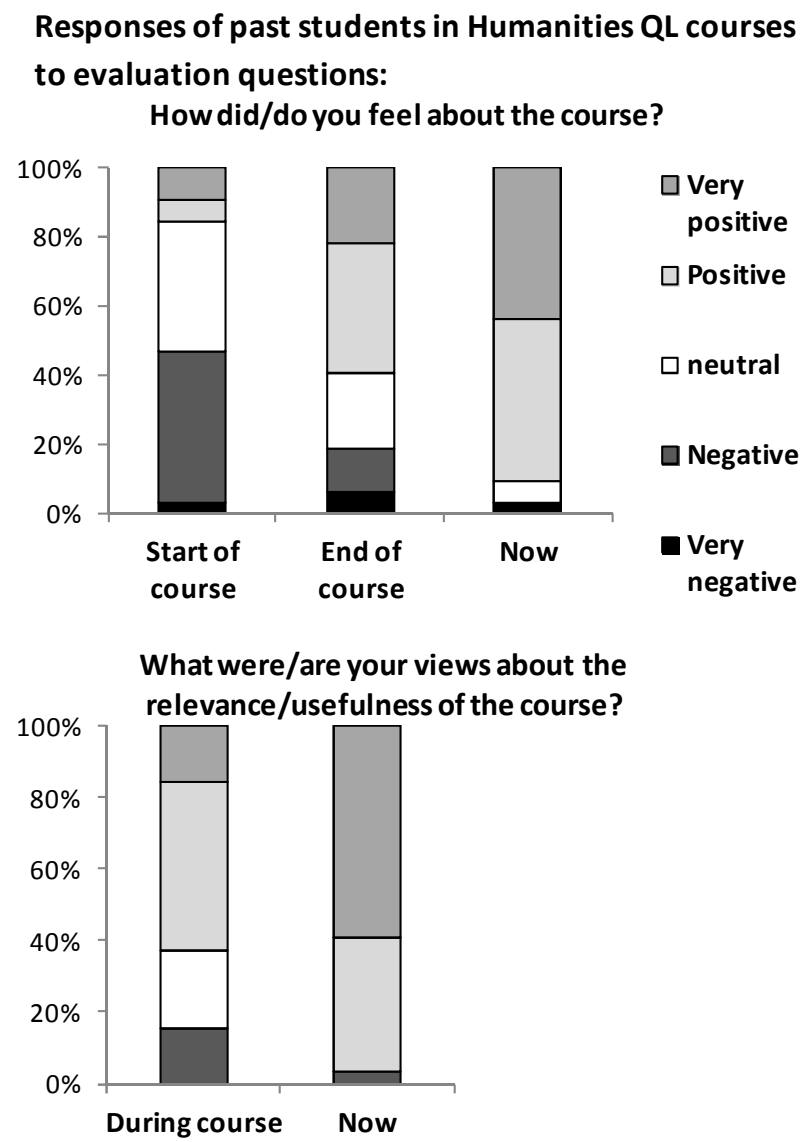

Figure 1. Summary of Student Evaluation Responses on Survey of Past Students of Humanities Course. Student perceptions of the course and its relevance improved over time after completing the course.

It is comments like the following, which students wrote in their e-mail responses, that motivate us in our ongoing efforts to address the curriculum challenges previously described:

"Initially felt it was something I was forced to do and as what we were learning was not (yet) relevant to the courses we were currently studying I felt it was a waste of time. Only became aware of its relevance and high value in use as I undertook courses in later years. What I had learnt really helped and I felt it gave me an advantage."

"I had no idea of the extent of its usefulness until I knew how much statistics was involved in Psychology. ... I made it to Psychology Honours because of this course. ... Furthermore, it is because of the small scale classes that I was able to grasp the content of the course. The intimacy allowed for more personal interaction with the lecturer, tutor, and other students. It was a fruitful and worthwhile experience. I definitely recommend it to all students in the first year who wish to proceed with Psychology. ..." 
We believe that for developing the QL of our students, we must firstly ensure that they have the necessary mathematical and statistical content knowledge and skills. However in a QL course there is little value in teaching de-contextualised mathematical and statistical content, so the challenge is to find ways within the context-based curriculum to improve student motivation and to navigate the difficulties that result from the tensions between the contexts and the mathematical and statistical content. This is the focus of our ongoing curriculum development and research.

\section{The QL Provision for First-year MBChB (Medical) Students}

Description of the Intervention. Since the year 2000, we have tested all firstyear entry-level students ${ }^{4}$ in our Health Sciences Faculty with an instrument designed to assess the QL competency of university students. The results of this testing have shown that many students lack quantitative concepts and techniques that medical courses appear to assume students will have. Systematic examination of the curriculum for the first-year integrated human biology/biochemistry/public health course (called Transitions in Health) revealed that the QL demands are extensive and very varied (Frith and Gunston 2011). Although all medical students have done mathematics at school, this does not necessarily mean that they are prepared for the QL demands of the curriculum. School mathematics does not include applying the mathematical techniques in real contexts and the statistical content of the school mathematics curriculum is very limited. As Steele and Kiliç-Bahi (2008) point out in their case study, "Even students who have taken several math courses are often confused by calculating percentage change and converting units, for example." This has been our experience also.

The core courses in the medical curriculum employ a "supported problembased learning approach" (Van Pletzen 2006:111) and integrate the learning in the various different traditional medical disciplines as well as the development of other competencies. It is within this learning environment that the Numeracy Centre provides an intervention for these students, which has the same general objectives as the course for Humanities and Law students described above.

The integration of the QL provision into the medical curriculum is addressed in the design of the relatively isolated QL learning experiences and assessment provided by the Numeracy Centre. This is done by designing learning materials that develop students' quantitative practices within the medical 'disciplinary contexts' that are being studied concurrently in the medical courses. Thus the QL provision is a component of the support provided for each of the cases studied in the supported problem-based learning (PBL) curriculum; there is little separation between the 'contexts' we use in our intervention and the 'disciplinary contexts.'

\footnotetext{
${ }^{4}$ In South Africa, students begin their medical studies straight after finishing secondary school.
} 
In practice the QL provision consists mainly of learning materials (worksheets that are a combination of resource materials, explanatory notes and exercises) for all first-year medical students, supported by compulsory weekly workshops for students identified by testing as needing assistance with completing the worksheets. In line with the conception of QL as social practice, the exercises in these worksheets make quite heavy demands on students' ability to comprehend and write academic language used to express quantitative concepts. An example extracted from these materials is included in Appendix B.

Table 2

Summary of the Quantitative Literacy Curriculum for the First Semester of MBChB

\begin{tabular}{|c|c|c|}
\hline Mathematical and statistical content & Some contexts used & $\begin{array}{l}\text { Examples of thinking/behaviour } \\
\text { required }\end{array}$ \\
\hline Ratios, direct proportion, percentages. & Birth rates. & $\begin{array}{l}\text { Appreciate the distinction between } \\
\text { relative proportions and absolute } \\
\text { quantities. }\end{array}$ \\
\hline Percentage change. & $\begin{array}{l}\text { Birth rates. } \\
\text { Cost of medicine. }\end{array}$ & $\begin{array}{l}\text { Appreciate the distinction between } \\
\text { relative change and absolute change. }\end{array}$ \\
\hline Indirect proportion. & Solutions (dilution). & Understand inverse relationships. \\
\hline $\begin{array}{l}\text { Significant figures and precision in } \\
\text { measurement. }\end{array}$ & $\begin{array}{l}\text { BMI. } \\
\text { Various measurements. }\end{array}$ & $\begin{array}{l}\text { Develop a feel for the connection } \\
\text { between variability and error in } \\
\text { measurements. }\end{array}$ \\
\hline Logarithms and logarithmic scales. & Hearing, $\mathrm{pH}$. & Think in terms of orders of magnitude. \\
\hline Exponential change. & Population growth. & $\begin{array}{l}\text { Understand the idea of changes in rates } \\
\text { of change. } \\
\text { Transfer ideas to unfamiliar contexts. }\end{array}$ \\
\hline $\begin{array}{l}\text { Representing frequency distributions: } \\
\text { Frequency tables } \\
\text { Percentage frequencies and cumulative } \\
\text { percentage frequencies. } \\
\text { Histograms and cumulative curves. } \\
\text { Box-and-whisker charts. }\end{array}$ & $\begin{array}{l}\text { Body weights and heights, } \\
\text { BMI }\end{array}$ & $\begin{array}{l}\text { Analyse a data set to choose } \\
\text { appropriate intervals for grouping of } \\
\text { data } \\
\text { Reason with inequalities } \\
\text { Translate between different } \\
\text { representations }\end{array}$ \\
\hline $\begin{array}{l}\text { Descriptive statistics: } \\
\text { Percentiles (including median, quartiles) of a } \\
\text { distribution. } \\
\text { Statistical measures for central tendency (mean } \\
\text { and median) and for spread (range, } \\
\text { interquartile range). }\end{array}$ & $\begin{array}{l}\text { Body weights and heights, } \\
\text { BMI. } \\
\text { Risk-taking behaviour. }\end{array}$ & $\begin{array}{l}\text { Make conceptual links between } \\
\text { different representations of same } \\
\text { concepts. } \\
\text { Generalise ideas from specific cases. }\end{array}$ \\
\hline $\begin{array}{l}\text { Graphs and functions: } \\
\text { Growth charts } \\
\text { Different representations: verbal, tabular and } \\
\text { graphical. } \\
\text { Rate of change - steepness of a graph at a } \\
\text { point. } \\
\text { Graphs of a variable and graphs showing the } \\
\text { rate of change of a variable. }\end{array}$ & $\begin{array}{l}\text { Growth charts: Body } \\
\text { weights and heights, BMI. } \\
\text { Enzymes and reaction rates. } \\
\text { Oxygen saturation curves. } \\
\text { Growth of a culture. }\end{array}$ & $\begin{array}{l}\text { Make connections between data } \\
\text { distributions and changes over time. } \\
\text { Interpret shapes of graphs in terms of } \\
\text { differences in rates of change. } \\
\text { Make connections between quantities } \\
\text { and rates of change of quantities. }\end{array}$ \\
\hline
\end{tabular}

The integrated Lifecycle course which is the core of the first-semester medical curriculum, deals with normal human development throughout the lifespan. At the same time, the students complete physics and chemistry courses. The QL, although tied to the structure of the Lifecycle course and assessed in the 
tests for this course, also includes some material designed to support the learning in chemistry and physics. In a similar manner, the QL for the second semester is associated with the integrated Transitions in Health course. Most of the QL material in the second-semester intervention, which includes a substantial series of spreadsheet-based computer learning materials, is closely integrated with the public health component of this course.

Table 3

Summary of the Quantitative Literacy Curriculum for the Second Semester of MBChB

\begin{tabular}{|c|c|c|}
\hline $\begin{array}{l}\text { Mathematical and statistical } \\
\text { content }\end{array}$ & Some contexts used & Examples of thinking/behaviour required \\
\hline $\begin{array}{l}\text { Ratios, direct proportion, } \\
\text { percentages. }\end{array}$ & $\begin{array}{l}\text { Epidemiology: incidence and } \\
\text { prevalence of disease: HIV, burns, } \\
\text { diarrhoea, TB. } \\
\text { Infant mortality rates. } \\
\text { Risk-taking behaviour. }\end{array}$ & $\begin{array}{l}\text { Apply the definitions of measures of extent of } \\
\text { disease in context. }\end{array}$ \\
\hline Percentage change. & TB data. & $\begin{array}{l}\text { Appreciate the distinction between relative } \\
\text { change and absolute change. }\end{array}$ \\
\hline $\begin{array}{l}\text { Data represented in text, tables } \\
\text { and charts (bar charts, stacked } \\
\text { bar charts. line charts). }\end{array}$ & $\begin{array}{l}\text { Infant mortality rates. } \\
\text { Incidence and prevalence of disease: } \\
\text { HIV, burns, diarrhoea, TB. } \\
\text { Risk-taking behaviour. }\end{array}$ & $\begin{array}{l}\text { Analyse information about data critically and } \\
\text { with understanding. } \\
\text { Integrate knowledge of ratios with knowledge } \\
\text { of data representations. } \\
\text { Make comparisons and recognise trends. } \\
\text { Express quantitative information graphically, } \\
\text { in tables and in clear English }\end{array}$ \\
\hline $\begin{array}{l}\text { Probability, measures of } \\
\text { association: } \\
\text { Proportions in data as estimates } \\
\text { of probability. } \\
\text { Risk ratio and odds ratio }\end{array}$ & $\begin{array}{l}\text { Hypertension. } \\
\text { Heart disease. }\end{array}$ & $\begin{array}{l}\text { Communicate the meaning of the value of a } \\
\text { measure of association as a result of a study. }\end{array}$ \\
\hline $\begin{array}{l}\text { Sampling. } \\
\text { Different types of study design: } \\
\text { cross-sectional, case-control, } \\
\text { cohort and experimental. }\end{array}$ & $\begin{array}{l}\text { Hypertension. } \\
\text { Heart disease. } \\
\text { Risk-taking behaviour. }\end{array}$ & $\begin{array}{l}\text { Appreciate the effects of sampling on the } \\
\text { reliability of results. } \\
\text { Analyse a description of a study. }\end{array}$ \\
\hline $\begin{array}{l}\text { Confidence intervals. } \\
\text { Relationship between a } \\
\text { confidence interval of a sample } \\
\text { statistic and the corresponding } \\
\text { population parameter (e.g. } \\
\text { means, proportions). }\end{array}$ & Risk-taking behaviour. & $\begin{array}{l}\text { Understand the difference between a } \\
\text { population distribution and a sampling } \\
\text { distribution. } \\
\text { Communicate the meaning of a confidence } \\
\text { interval. }\end{array}$ \\
\hline $\begin{array}{l}\text { Hypothesis testing and p- } \\
\text { values. } \\
\text { p-value in the context of } \\
\text { reported results of studies. }\end{array}$ & $\begin{array}{l}\text { Interpersonal violence. Risk-taking } \\
\text { behavior. }\end{array}$ & $\begin{array}{l}\text { Appreciate the concepts of statistical } \\
\text { significance. }\end{array}$ \\
\hline $\begin{array}{l}\text { Correlation and concept of best- } \\
\text { fit line: }\end{array}$ & $\begin{array}{l}\text { Exercise and fitness. } \\
\text { Infant mortality rates. } \\
\text { Diarrhoea. }\end{array}$ & $\begin{array}{l}\text { Appreciate the difference between correlation } \\
\text { and causation. } \\
\text { Interpret the degree of scatter of points and/or } \\
\text { value of correlation coefficient in terms of a } \\
\text { rough description of degree of association. }\end{array}$ \\
\hline
\end{tabular}

Tables 2 and 3 present a summary of the QL curriculum in the first and second semesters respectively. Unlike the intervention itself, this summary is structured around the main mathematical and statistical content so as to expose 
the concepts we have identified as most necessary to enable a first-year medical student to understand the medical contexts in the first year and to prepare for subsequent years. The last column lists examples of some of the higher-order thinking and behaviour that we try to develop in our intervention.

Challenges in the $\mathbf{Q L}$ for $\mathrm{MBChB}$ Intervention. It is desirable to aim to integrate the QL provision into the students' experience of the contexts studied in the medical curriculum. Ideally this could be done by ensuring that the lecturers of the medical courses are fully aware of the quantitative demands made by their curricula and the likely difficulties that students could experience with them, as well as knowing how to address these difficulties within their courses. For various reasons (historical, political, structural and practical), we cannot insist on this model, although we do work where we can with the lecturers in some of the medical courses to help them understand the QL demands of their curriculum. These considerations have led to the QL intervention for the students in our case being provided by the Numeracy Centre staff in specifically scheduled classes and with only partially integrated assessment.

In the teaching of these workshops we experience few of the difficulties relating to tensions between content and context (as described above for the Law and Humanities course). This is presumably partly because the contexts used for the QL materials are mostly the same ones currently being studied by the students in their PBL cases, which improves student motivation. There are, however, always some students who are resistant to attending the QL workshops and completing the computer-based learning materials. The MBChB curriculum is very fast-paced and demanding and this leads to a number of students applying strategic study techniques, which involve deciding that they can afford not to engage with the QL materials. This would not be possible in a curriculum where the QL development was fully integrated.

The results of the evaluation of the opinions of those students who are obliged to attend the workshops reveal that students' responses to the QL intervention are generally positive. However, the answers to open-ended questions show that many students value the workshops as an efficient way to prepare for assessments rather more than for providing understanding that supports their learning in the medical contexts.

The comparison of the results at the end of the year for the students who attended workshops in the second semester (workshop students) with those who did not (non-workshop students) provides evidence that the workshops are indeed effective in terms of improving students' performance on the assessment questions. An example from 2009 is shown in Figure 2. 


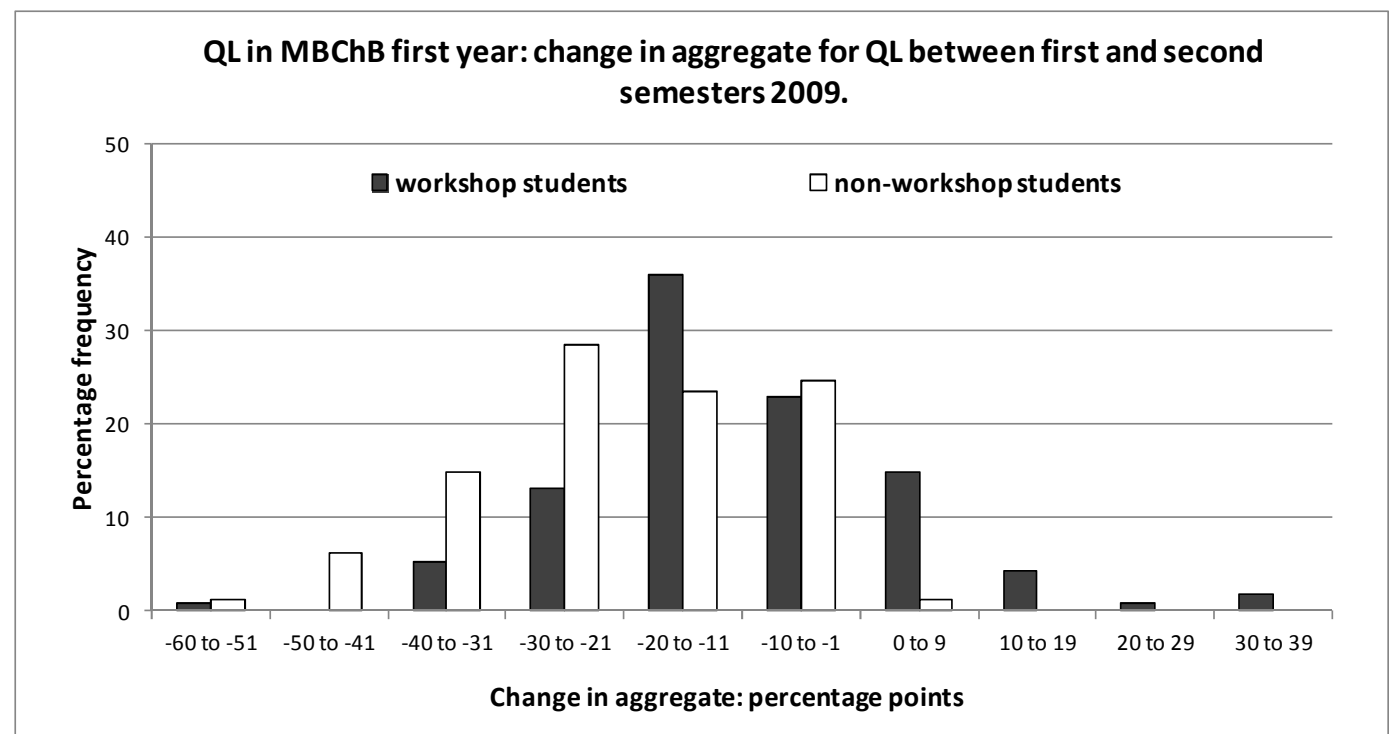

Figure 2. Distributions of Changes in Aggregate Marks between First and Second Semesters for QL Assessment Questions in 2009. Students who attended workshops had a smaller decrease in percentage points between the first and second semesters

This chart shows the distributions of the change between the aggregate marks for the quantitative literacy assessment questions in the first and the second semesters for the two groups, those who attended workshops in the second semester (mean change -10\%) and those who did not (mean change -21\%). These reductions in marks for QL questions (although they might seem to suggest that our intervention has a negative effect on students' QL ability) in fact result from the increase in the level of difficulty of the QL in the second-semester course. The difference between the means of the two distributions is statistically significant at the level above $99 \%$ (using a $t$-test). It is clear that there is a tendency for the non-workshop students to suffer a reduction in performance to a greater extent than the workshop students.

The pragmatic focus of the students on preparation for assessments leaves open the question of whether our partially integrated intervention is successfully contributing to the development of students' quantitative practices in the medical disciplines. One challenge is to find ways to evaluate whether students successfully transfer what they learn from the QL materials and workshops to their other courses in their first year and to courses in later years.

\section{Concluding Reflections}

My argument is that the theoretical understanding of the nature of QL as practice in context dictates that the best kind of intervention for developing students' QL 
would be to work with disciplinary lecturers to ensure that they develop the students' QL practices in the context of the learning of the disciplines. It is easy to see that this 'ideal' situation is not likely to be achievable in all cases.

Even though the need to develop students' QL is recognized at the level of policy at our university, it is not universally acknowledged by disciplinary lecturers and curriculum designers across the university. Since the Numeracy Centre has the goal of promoting QL development, we welcome opportunities to intervene in the curriculum, even if they do not promise a structure that is ideal in terms of our theoretical understanding of QL. Two such interventions have been described in this article. At the same time, we actively advocate the idea of integration of QL provision into curricula and take advantage of those opportunities that arise to work with lecturers in an integrated way, and thus improve the alignment between our conceptualisation of QL and our educational practice.

Our experience of such integrated interventions is that they also present challenges, the major one being that a great deal of time is required for such work (by both the disciplinary lecturers and ourselves). Lecturers who are enthusiastic about collaboration often become less so when they realize how much time will be involved in becoming more knowledgeable about QL and in assisting the Numeracy Centre lecturers in becoming more knowledgeable about their discipline. Beside this consideration, collaborative materials development is bound to be more time-consuming than working by oneself. It is not surprising therefore that many would prefer to give us some time with the students to address their QL development in whatever way we prefer. This is particularly the case if the disciplinary lecturers feel themselves to be inadequate in terms of their own QL or feel threatened by exposure of their perceived inadequacy to quantitative literacy 'experts.'

Our theoretical view of the nature of QL not only stresses the idea of QL as practice, but also emphasizes the importance of communication of quantitative information and ideas as part of that practice. As we become more familiar with the literature dealing with academic literacy development and continue to reflect on the successes and challenges of our work we are becoming more and more aware of the inescapable overlap between the development of students' QL and their language development. Where before we might have thought that students were just not paying attention in class, or not working hard enough, we now realise that our not having paid sufficient attention to language and academic literacy development issues may in fact be behind some of the students' difficulties. For example, we require students to describe and compare trends revealed by charts, but particularly for second-language students, we think we probably have not been making our implicit expectations of an adequate answer explicit enough. Dingman and Madison (2010) point out that it is necessary to 
help students to identify language cues in problem statements, and we are increasingly aware of this requirement. As a result we believe we should play a more active role in the development of students' appropriate use of language in academic writing and in their ability to read text in which quantitative information is embedded. This is an area where we need to achieve more integration and engage in collaborative teaching and curriculum development particularly with language development colleagues. This should assist students in developing the necessary reading and writing competencies for understanding and expressing quantitative information and concepts in context.

The two first-year interventions of the Numeracy Centre which are described in this article deviate from the 'ideal' degree of integration to different extents, and in both cases the challenge of some students' lack of motivation arises, although less so in the more integrated medical intervention. This problem of students' lacking motivation is in my opinion likely to be inherent in this kind of 'foundation' provision, as students experience only the foundations and do not yet know what structures are to be built upon them. We have evidence from surveys of past Humanities students that many of them grew to appreciate the value of the QL course later in their programmes, but it remains a challenge to find ways to motivate students in the course on the basis of promises of future relevance. In the words of Madison and Steen (2009, p. 11) "You have to work at finding something that students are interested in."

In our experience the medical students are more positive in general about the value of the QL intervention in medicine than the Humanities and Law students are about their course, which is probably because the contexts used in the medical intervention are the ones being studied concurrently in the courses in medicine. This supports the assertion that student motivation to engage with a contextdriven curriculum is very dependent on their interest in and perception of the relevance of the contexts used. It also provides further argument in favour of integrating QL provision into the disciplinary curriculum wherever possible, especially into the subsequent years of study where the need for QL can often be seen to be more relevant. However in practice this is often not possible and more or less 'stand-alone' QL interventions are the pragmatic alternatives. Some of the major curriculum challenges in designing such interventions are finding suitable contexts and convincing the students of their relevance.

\section{Acknowledgements}

I am grateful to my colleagues in the Numeracy Centre whose work and ideas have contributed to this article. I also thank my colleagues in the Health Sciences Faculty who have provided opportunities for our work and in the Language Development Unit who have contributed to our thinking. 
Ashwin, P. 2009. Analysing teaching-learning interactions in higher education. London: Continuum.

Bernstein, B. 1990. The structuring of pedagogic discourse. Volume IV. Class, codes and control. London: Routledge.

2000. Pedagogy, symbolic control and identity. Boston: Rowman \& Littlefield.

Dingman, S.W. and B.L. Madison. 2010. Quantitative reasoning in the contemporary world, 1: The course and its challenges. Numeracy. 3 (2) http://dx.doi.org/10.5038/1936-4660.3.2.4

Frith, V. and G. Gunston. 2011.Towards understanding the quantitative literacy demands of a first-year medical curriculum. African Journal of Health Professions Education. 3 (1): 19-23. http://www.ajhpe.org.za/index.php/ ajhpe/article/viewFile/120/40 (accessed 6 July, 2011).

Frith, V. and R. N. Prince. 2006. Quantitative literacy. In Access and entry-level benchmarks: the National Benchmark Tests Project, ed. H. Griesel, 28-34; 47-54. Pretoria: Higher Education South Africa. http://www.heenrol.ac.za/nishe/Access\&entrylevelMay2006.pdf (accessed 6 July, 2011).

- 2009. A framework for understanding the quantitative literacy demands of higher education. South African Journal of Higher Education, 23 (1): 8397.

Frith, V., K. Le Roux, P. Lloyd, J. Jaftha, D. Mhakure and S. Rughubar-Reddy. 2010. Tensions between context and content in a quantitative literacy course at university. In Proceedings of the sixth mathematics education and society conference (MES6), ed. U. Gellert, E. Jablonka and C. Morgan, 230-240. Berlin: Freie Universität Berlin. http://www.ewi-psy.fuberlin.de/en/v/mes6/documents/research_papers/Frith_et_al_MES6.pdf?128 6354774 (accessed 18 July, 2011).

Gal, I. 2005. Statistical literacy: Meanings, components, responsibilities. In The challenge of developing statistical literacy, reasoning and thinking, ed. D. Ben-Zvi and J. Garfield, 47-78. New York: Kluwer. http://dx.doi.org/ 10.1007/1-4020.2278-6_3 , M. van Groenestijn, M. Manly, M. J. Schmitt and D. Tout. 2005. Adult numeracy and its assessment in the ALL Survey: A conceptual framework and pilot results. In Measuring adult literacy and life skills: New frameworks for assessment, ed. T. Scott Murray, Y. Clermont and M. Binkley, 137-191. Ottawa: Statistics Canada. http://www.statcan.gc.ca/pub/89-552-m/89-552m2005013-eng.pdf (accessed 6 July, 2011).

Gee, J. 1990. Social linguistics and literacies: Ideology in Discourses. Basingstoke: The Falmer Press. 
Jacobs, C. 2007. Mainstreaming academic literacy teaching: Implications for how academic development understands its work in higher education. South African Journal of Higher Education, 21 (7): 870-881.

Kelly, S., B. Johnston and M. Baynham. 2007. The concept of numeracy as social practice. In The adult numeracy handbook: Reframing adult numeracy in Australia, ed. S. Kelly, B. Johnston and K. Yasukawa, 35-49. Sydney: NSW Adult Literacy and Numeracy Australian Research Consortium.

Lerman, S. and R. Zevenbergen. 2004. The socio-political context of the mathematics classroom. In Researching the socio-political dimensions of mathematics education: Issues of power in theory and methodology, ed. P. Valero and R. Zevenbergen, 27-42. Dordrecht: Kluwer Academic Publishers. http://dx.doi.org/10.1007/1-4020-7914-1_4

Madison, B.L. and L.A. Steen. 2009. Confronting challenges, overcoming obstacles: A conversation about quantitative literacy. Numeracy. 2 (1) http://dx.doi.org/10.5038/1936-4660.2.1.2 (accessed 10 October, 2011).

McKenna, S. 2009. Cracking the code of academic literacy: An ideological task. In Beyond the university gates: Provision of extended curriculum programmes in South Africa. Proceedings of the January 2009 Rhodes University Foundation Seminar, ed. C. Hutchins and J. Garraway, 11-28. Grahamstown: Rhodes University. http://www0.sun.ac.za/heltasa/file.php/1/Foundation/Rhodes_Foundation_Se minar_book_final.pdf (accessed 6 July, 2011).

Mosenthal, P.B. 1996. Understanding the strategies of document literacy and their conditions of use. Journal of Educational Psychology, 88 (2): 314-332. http://dx.doi.org/10.1037/0022-0663.88.2.314

Roth, W., L. Pozzer-Ardenghi and J. Y. Han. 2005. Critical graphicacy: Understanding visual representation practices in school science. Dordrecht: Springer.

Scott, I., N. Yeld and J. Hendry. 2007. Higher Education Monitor No. 6: A case for improving teaching and learning in South African higher education. Pretoria: The Council on Higher Education. http://www.che.ac.za/documents/ d000155/HE_Monitor_6_ITLS_Oct2007.pdf (accessed 6 July, 2011).

Steele, B. and S. Kiliç-Bahi. 2008. Quantitative literacy across the curriculum: a case study. Numeracy. 1 (2) http://dx.doi.org/10.5038/1936-4660.1.2.3

Street, B. 2005. Applying New Literacy Studies to numeracy as social practice. In Urban literacy: Communication, identity and learning in development contexts, ed. A. Rogers, 87-96. Hamburg: UNESCO Institute for Education.

- and D. Baker. 2006. So, what about multimodal numeracies? In Travel notes from the New Literacy Studies, ed. K. Pahl and J. Rowsell, 219-233. Clevedon: Multilingual Matters Ltd. 
Van Pletzen, E. 2006. A body of reading: making 'visible' the reading experiences of first-year medical students. In Academic literacy and the languages of change, ed. L. Thesen and E. van Pletzen, 204-129. London: Continuum.

Venkat, H., L. Bowie and M. Graven. 2009. Positions and purposes for contextualisation in mathematics education in South Africa. African Journal of Research in Mathematics Science and Technology Education Special Issue 2009: 81-95.

Yeld, N. 2009. The National Benchmark Tests Project: Addressing student educational needs in the tertiary education system. In Recession and recovery, ed. J. Hofmeyer, 76-83. Cape Town: Institute for Justice and Reconciliation. http://www.ijr.org.za/publications/pdfs/IJR_TA_Chapter3.pdf (accessed 6 July, 2011).

Zevenbergen, R, P. Sullivan and J. Mousley. 2002. Contexts in mathematics education: Help? Hindrance? For whom? In Proceedings of the third mathematics education and society conference (MES3), ed. $\mathrm{P}$ Valero and $\mathrm{O}$ Skavsmose, 1-9. Copenhagen: Centre for Research in Learning Mathematics. http://mes3.learning.aau.dk/Papers/Zevenbergen_et_al.pdf (accessed 6 July, 2011). 


\section{Appendix A:}

\section{Example of Extract from Learning Materials from QL Course for Law and Humanities Students}

\section{Unit 4: Prisons in South Africa}

In this unit we will read extracts from a report about overcrowding of prisons in South Africa:

Giffard, C and Muntingh, L. (2006) The Effect of sentencing on the size of the South African prison population. Open Society Foundation for South Africa, Newlands, SA

\section{Activity 1:}

In this activity you will be looking at the many ways in which the mathematical idea of change can be described using language. The quantitative ideas encountered here include absolute vs relative size, absolute vs relative change, rate of change, graphical representation.

Read the following extract from the beginning of the report and then answer the questions below.

\section{Executive Summary}

South Africa has a serious prison overcrowding problem. The total number of prisoners has grown steadily and dramatically over the last 11 years. The cause of the increase has changed during this time. Between 1995 and 2000, the major reason that the prison population was rising was the massive increase in the number of unsentenced prisoners. After 2000, the number of unsentenced prisoners stabilised, and then began to decrease. But the prisoner population continued to grow, now as a result of an increase in the number of sentenced prisoners. This growth continues, despite the fact that the number of offenders sent to prison is decreasing. The bulk of this increase consists of prisoners serving long sentences. Thus, the rate of release of sentenced prisoners is slowing down.

Prisoners serving longer sentences make up an increasing proportion of the prisoner population. Mathematical projections show that the longer sentences are driving up the total prisoner population rapidly. These projections suggest that, if current trends are maintained, the growth in the number of long-term prisoners will increase the prison population to over 226000 by 2015 . Half of these will be prisoners serving sentences of between 10 and 20 years, $15 \%$ will be serving more than 20 years and about $90 \%$ will be serving sentences longer than 7 years. 
1. The second paragraph starts with the statement: "Prisoners serving longer sentences make up an increasing proportion of the prisoner population". If you assume that you do not know anything else about the situation, which of the following conclusions is valid?

A. There are increasing numbers of prisoners with longer sentences

B. There are increasing numbers of prisoners in total

C. The fraction of the prison population that is serving longer sentences is increasing.

D. There are decreasing numbers of unsentenced prisoners and prisoners with shorter sentences.

E. The ratio of short-term prisoners to long-term prisoners is decreasing.

2. For each of the following statements from the text, choose the three statements that you think are most accurately expressing the same idea:

a. "The total number of prisoners has grown steadily ...."

A. The total number of prisoners has become more and more ...

B. There has been a continuous increase in the total number of prisoners

...

C. The total number of prisoners has increased consistently ....

D. The total number of prisoners has increased at a constant rate ...

E. There has been a fairly constant growth in the total number of prisoners ...

F. The total number of prisoners has grown faster and faster ...

b. "The rate of release of sentenced prisoners is slowing down."

A. The number of sentenced prisoners who are being released each year is decreasing

B. The prisons have stopped releasing sentenced prisoners.

C. Fewer and fewer sentenced prisoners are being released each year

D. The release rate for sentenced prisoners is negative

E. The prisons are releasing sentenced prisoners at a decreasing rate.

F. Fewer sentenced prisoners are being released.

3. Explain how it is possible that the prison population continues to grow even though the number of offenders admitted to prison is decreasing.

4. What is a "mathematical projection"?

5. What does it mean to say that "the longer sentences are driving up the total prisoner population rapidly"?

6. Using information in the last sentence, sketch a pie chart showing the projected composition of the prison population in 2015, broken down into four categories based on length of prison sentence. 


\section{Appendix B:}

\section{Example of Extract from Learning Materials from QL Intervention for Medical Students.}

\section{Incidence of TB in the Western Cape.}

Read the following extract from "Cape Town TB Control Progress Report 1997-2003" (Downloaded from the Health Systems Trust website at: http://www.hst.org.za/uploads/files/tb_ct.pdf)

\section{"4.1.2 INCIDENCE RATE (CASE DETECTION RATE)} In spite of $66 \%$ increase in the total TB caseload over the past seven years, when population growth is accounted for, the TB incidence rate has only increased by $30 \%$ over this period, with a high of $678 / 100000$ population in 2003 (Table 2)"

Table 2: Incidence (Case detection) Rate 1997-2003

\begin{tabular}{|c|c|c|}
\hline Year & $\begin{array}{c}\text { New TB cases registered } \\
\text { All TB }\end{array}$ & $\begin{array}{c}\text { Case-detection Rate } \\
\text { /100 000 population } \\
\text { All TB }\end{array}$ \\
\hline 1997 & 13870 & 521 \\
\hline 1998 & 14970 & 520 \\
\hline 1999 & 15769 & 530 \\
\hline 2000 & 17244 & 562 \\
\hline 2001 & 18361 & 581 \\
\hline 2002 & 20950 & 638 \\
\hline 2003 & 22999 & 678 \\
\hline
\end{tabular}

2.1 Verify that there was a "66\% increase in the total TB caseload" over the period 1997 to 2003 .

2.2 Why is the Incidence Rate in this case also called the "Case Detection rate"?

2.3 Explain how it is possible that the total number of cases increased by $66 \%$ while the Incidence Rate increased by "only" $30 \%$.

2.4 Calculate the population at risk in each of the years 1997 and 2003. Use these values to get an estimate of the population growth of Cape Town between 1997 and 2003.

2.5 Plot an appropriate chart to illustrate how the number of all registered TB cases and the Incidence (Case Detection) Rate changed over the years 1997 to 2003. (A bar chart 
would not be incorrect here, but can you think of another way that will make it easier to see trends?)

2.6 Use your chart to make a prediction for the Incidence Rate of TB in Cape Town in 2006.(Now try to find out what the incidence rate for 2006 was actually determined to be.)

Now look at the following data that was published by the Western Cape Department of Health at http://www.capegateway.gov.za/Text/2006/5/tb_stats_2006.pdf

\begin{tabular}{|c|c|c|c|c|}
\hline Year & $\begin{array}{c}\text { Newly } \\
\text { Registered TB } \\
\text { cases } \\
\text { Cape Town }\end{array}$ & $\begin{array}{c}\text { Newly } \\
\text { Registered TB } \\
\text { cases } \\
\text { Western Cape }\end{array}$ & $\begin{array}{c}\text { Incidence Rate } \\
/ 100000 \\
\text { Cape Town }\end{array}$ & $\begin{array}{c}\text { Incidence Rate } \\
/ 100000 \\
\text { Western Cape }\end{array}$ \\
\hline 1997 & 13870 & 27509 & 521 & 689 \\
\hline 1998 & 14970 & 28843 & 520 & 709 \\
\hline 1999 & 15769 & 31536 & 530 & 761 \\
\hline 2000 & 17244 & 33665 & 562 & 797 \\
\hline 2001 & 18361 & 40144 & 581 & 933 \\
\hline 2002 & 20950 & 42123 & 638 & 960 \\
\hline 2003 & 23329 & 44414 & 687 & 993 \\
\hline 2004 & 24414 & 44145 & 810 & 967 \\
\hline 2005 & 26754 & & 874 & \\
\hline
\end{tabular}

2.7 Note that the data for Cape Town for the year 2003 is not the same as in Table 2 above. Can you think of a reason?

2.8 Plot the data for Cape Town for the years 2004 and 2005 onto the chart which you plotted above.

2.9 Explain why it looks as though there might be a mistake in the Incidence Rate data for 2004.

2.10 Look at the value for the total number of TB cases registered in the Western Cape in 2004. In the light of the other values in the first two columns of the table, do you trust this figure? Explain.

2.11 Compare the incidence rate figures for Cape Town with those for the Western Cape as a whole. What does this comparison tell you about the incidence of TB in parts of the province outside of Cape Town? Do you predict that the incidence rate in parts of the Western Cape that are outside of Cape Town is higher, the same or lower than the incidence rate for the province as a whole? 